\title{
AGRICULTURA FAMILIAR NA AMÉRICA LATINA: A DIFUSÃO DO CONCEITO E A CONSTRUÇÃO DE SUJEITOS POLÍTICOS
}

\section{FAMILY FARMING IN LATIN AMERICA: THE SPREAD OF THE CONCEPT AND THE SUBJECT OF POLITICAL CONSTRUCTION}

RESUMO: O presente artigo analisa a "agricultura familiar" na América Latina, como manifestação dos modos de vida e complexidades da região. Debate-se a categoria como "conceito-síntese" das rupturas e continuidades do Agro latino-americano.

Palavras-chave: Agricultura familiar. América Latina. Conceitos. Diversidade.
ABSTRACT: This article analyzes the "family farming" in Latin America, as a manifestation of lifestyles and complexities of the region. The category is discussed as "concept-synthesis" of ruptures and continuities of Agro Latin American.

Keywords: Family farming. Latin America. Concepts. Diversity.

\footnotetext{
${ }^{1}$ Professor de Direito no Centro Universitário de Desenvolvimento do Centro Oeste - UNIDESC e nas Faculdades Integradas da União Educacional do Planalto Central - FACIPLAC. Ex-assessor de Juiz na Comarca de Luziânia/GO. E-mail: Ifperdigao@gmail.com.
} 


\section{INTRODUÇÃO}

A América Latina vive, no século XXI, um momento distinto na relação entre agricultura e desenvolvimento. O aumento da demanda por terras, água e alimentos, a estrangeirização e grilagem de glebas, a persistência da pobreza rural e a alta concentração fundiária são exemplos de processos sociais e econômicos que colocam em evidência a dinâmica dos territórios, dos atores estatais, da governança institucional e as categorias sociais relacionadas à terra.

Assim, desde a primeira década dos anos 2000, cresce o interesse de políticos, acadêmicos e movimentos sociais sobre a temática da agricultura familiar na América Latina. Nos países latino americanos é crescente a necessidade de estabelecer definições mínimas, ainda que no âmbito jurídico, sobre o que seja a agricultura familiar, seu espaço político, econômico e social.

Não faltam razões estratégicas para tal preocupação, pois a agricultura familiar compreende diversos segmentos sociais e econômicos que, para além de qualquer abstração, respondem tanto pela maior parte da produção de alimentos, quanto pelos maiores bolsões de pobreza rural na América Latina. Segundo estudos da Comunidade Andina (2011), FAO e Banco Interamericano de Desenvolvimento (FAO/BID, 2007), os agricultores familiares são $14 \%$ da população total latino-americana. Geram entre $30 \%$ e 40\% de seu Produto Interno Bruto (PIB) e mais de $60 \%$ dos empregos rurais. Dois, em cada três agricultores latino-americanos, são agricultores familiares. Em termos de unidades produtivas, representam $80 \%$ delas e ocupam entre $30 \%$ e $60 \%$ da superfície agropecuária e florestal da América Latina. Por fim, de forma geral, estima-se que ao menos 100 milhões de pessoas dependem desse setor.

Além disso, o grupo concentra parte considerável da cultura e identidade dos povos, promove e impacta a preservação da biodiversidade, ao tempo em que sua produção 
responde a "los gustos y preferencias de los consumidores y del mercado en general" (SALCEDO e GUZMAN, 2014, p. 17). Portanto, entender a agricultura familiar latinoamericana é parte de um esforço considerável de se compreender o que seja a América Latina em suas complexidades e diversidades.

Nessa linha, o presente trabalho, através de pesquisa bibliográfica, aborda o espaço sociocultural da agricultura familiar latino-americana, focando sobre as rupturas, contradições e reminiscências históricas que, de alguma forma, compõem o quadro mais amplo da(s) identidade(s) latino-americana(s) no meio rural.

Para tanto, no primeiro tópico discute-se, brevemente, as dificuldades que permeiam as noções do que seja a América Latina e, por extensão, a de agricultor familiar latino americano. Na sequência, analisa-se a ideia de agricultura familiar na América Latina, focando na difusão e reconhecimento do conceito e da categoria social (segundo tópico). No terceiro tópico, debate-se, a diversidade desse setor na América Latina, visitando algumas definições técnicas adotadas para entender uma relativa convergência conceitual. Por fim, no quarto tópico, de forma geral e reflexiva, lançamos um olhar sobre as rupturas e continuidades que a agricultura familiar representa dentro das complexidades agrárias latino-americanas.

\section{AMÉRICA LATINA E AGRICULTURA FAMILIAR}

A utilização do termo "América Latina" consolidou-se após a Segunda Guerra Mundial (principalmente por meio dos organismos políticos multilaterais) e, historicamente, não constitui uma ideia homogênea e clara. A busca por "uma identidade latino-americana, ou das identidades latino-americanas tem sido objeto, há quase dois séculos" de diversos estudos e pesquisas, sem que haja uma resposta unívoca para definir essencialmente o que seja a América Latina. Tal busca identitária "parece infinita, pois se reconstrói de acordo com os interesses dos seus mais variados grupos, em determinados contextos históricos" (FARRET; PINTO, 2002, p.39). 
Não obstante seja uma preocupação centenária ${ }^{2}$, trabalhos recentes vêm resgatando a importância do tema. Essa vertente de estudos leva em conta não somente o cenário social e econômico europeu que outros pensadores já enfatizavam, mas principalmente o imaginário moderno sobre as extensões além-mar. Assim, a história da identidade latino-americana é reconhecida também através da "história dos diversos nomes da América e das razões pelas quais estes nomes foram impostos" (ROJAS MIX, 1991, p. 61-62).

Apesar de nascer oficialmente, em 1492, como "Novo Mundo", a ideia e o termo "América Latina" predominou historicamente e foi consolidado após a Segunda Guerra Mundial. Contudo, antes disso, a região foi também nomeada como América, IndoAmérica, Afro-América, Hemisfério Ocidental, Nuestra América e Labirinto LatinoAmericano. Essas e outras denominações, enquanto transfigurações nacionais e continentais interessam para a discussão deste trabalho no ponto em que revelam a América Latina como um continente que se traduz em "um vasto arquipélago de nações diferentes e estranhas entre si, buscando a integração e vivendo a fragmentação" (IANNI, 2000, p. 02).

Para Dussel, a América não somente foi a primeira periferia do sistema-mundo como também a primeira oportunidade de acumulação primitiva do capital (CASTROGOMEZ, 2005), sendo “inventada" pelo mercantilismo, modificada pelo colonialismo, transformada pelo imperialismo e transfigurada pelo globalismo, razão pela qual:

Nunca adquire sua plena fisionomia, seja como um todo, seja em suas nações. Está contínua e reiteradamente determinada pelas configurações e os movimentos internacionais, transnacionais ou mundiais. Tanto é assim que vários dos seus países têm nomes de mercadorias; todos fundados como províncias do mercantilismo e entrando no século 21 como províncias do globalismo (IANNI, 2000, p. 03).

\footnotetext{
2 O ponto de partida da arqueologia do nome "América Latina" se inicia com o artigo do historiador norte-americano John Leddy Phelan, "Pan-Latinism, French Intervention in Mexico (1861-1867) and the Genesis of the Idea of Latin América", publicado em 1968. Seu impacto no meio acadêmico foi enorme, podendo ser considerado até os dias de hoje como a referência bibliográfica predominante sobre o tema (FARRET; PINTO, 2011, p.35).
} 
Diante dessa trajetória histórica, o conceito de América Latina e de identidade latino-americana foram pautados por interpretações divergentes, "concebidas de um lado, por uma literatura dominante - de origem colonizadora -, que interpretava a região negativamente e, de outro pela teoria regionalista, composta predominantemente por intelectuais de origem latina" (SOUZA, 2011, p. 30). O termo América Latina, neste trabalho, diz respeito, do ponto de vista geopolítico, à área que abarca mais de 700 milhões de habitantes e envolve ao todo, 12 países da América do Sul, 07, da América Central e 14 do Caribe, ou seja, países que estão abaixo do Rio Grande - rio que separa México dos EUA, totalizando 21.000 quilômetros quadrados, com os idiomas português, espanhol, inglês, além de centenas de línguas regionais e nacionais, ligadas aos povos indígenas, afrodescendentes e muitos outros povos originários e tradicionais (ARAÚJO, 2006; SOUZA, 2011).

Não obstante essa delimitação, permanece um esforço para a "busca de uma visão de si", isto é, de "algum significado essencial" para entender o que vem a ser América Latina ou quais os elementos mais básicos dessa definição (IANNI, 2000, p. 02). A legitimação dessa identidade representa entre outros significados o reconhecimento de sua cultura, modo de vida, língua, costumes entre outras especificidades inerentes ao grupo social. A composição da identidade latino americana também pressupõe estas prerrogativas (SOUZA, 2011, p. 34).

Essa busca inclui (re)conhecer cuidadosamente uma complexa trama de relações políticas, sociais, econômicas e culturais. Para tal, dentre as diversas abordagens possíveis, a dinâmica das categorias sociais nos permite conhecer uma das faces da América Latina. Trata-se de lançar um olhar sobre grupos que, a exemplo dos agricultores familiares e camponeses, promovem rupturas e continuidades históricas. Assim, no bojo das diversas categorias sociais que nos permitem a tentativa de compreender as peculiaridades da América Latina, existem os agricultores familiares. Eles se relacionam com diversas 
temáticas regionais, em especial, a segurança alimentar, geração de emprego agrícola, mitigação da pobreza, conservação da biodiversidade e tradições culturais.

Não obstante seja de importância socioeconômica reconhecida mundialmente e atestada pelos números da Organização das Nações Unidas para a Alimentação e a Agricultura (FAO), a agricultura familiar é um elemento de complexidade latino-americana. Nesse sentido, "a cultura e a heterogeneidade socioeconômica que caracterizam o setor da agricultura familiar entre os países da América Latina e Caribe se replicam no interior de cada um deles" (SALCEDO; GUZMAN, 2014, p. 19) e, dessa forma, abordá-la é conhecer as lutas por terra, poder, capital e direitos, que dizem respeito à definição mais ampla das próprias realidades latino-americanas.

Assim, dentre os desafios de se conceber o que seja a "América Latina" inclui-se a temática da "agricultura familiar latino-americana", que desafia uma definição comum entre os países da região. Mais que isso, a categoria representa um traço marcante de diversidade, contradições e potencialidades (realizadas e latentes) da América Latina, em sua perspectiva rural.

\section{A IDEIA DE AGRICULTURA FAMILIAR NA AMÉRICA LATINA}

Um dos conceitos mais difundidos (e antigos) de agricultura familiar remonta aos Estados Unidos. A ideia de Family Farming, originada no século XX naquele país, definiu uma vertente de estudos sobre agricultura familiar, focando na predominância da mão-deobra da família na produção e na vida rural norte-americana. Contudo, a concepção de Family Farming norte-americana não basta para compreender a complexidade da agricultura familiar latino-americana.

Volvendo os olhos à América Latina, a ideia de agricultura familiar encontrou não somente uma prática, como também conceituações específicas à sua realidade. Tais definições começaram a ser formadas no fim do século XIX e início do século XX, influenciadas por estudos que atribuíam à paysannerie (campesinato), a função de 
estabilização e coesão das relações sociais. Desde então, múltiplas abordagens históricas e sociológicas reconheceram o campesinato como uma classe social particular, marcada por um estreito laço entre terra e comunidade, bem como por uma cultura peculiar. Nesse rol, no início do século XX, o trabalho seminal do russo Alexander Chayanov lançou novas luzes sobre o tema, destacando que a atividade econômica campesina seria estimulada pela necessidade de responder às demandas de subsistência da unidade familiar. Assim, a obra "Teoria da unidade econômica camponesa" propôs entender a economia camponesa a partir de seu caráter familiar, ou seja, não como uma estrutura tipicamente capitalista (orientada pelo valor de troca), mas por outras formas de produção e integração (valores de uso) (BARRIL; ALMADA, 2007, p. 03).

Nesse contexto, as políticas agrícolas e seus impactos sobre a agricultura familiar na América Latina têm sido periodizados ${ }^{3}$. As mudanças são interpretadas levando-se em conta uma fase (de 1950 a 1980) marcada pelos modelos de Estado centralizadores e associados a ditaduras militares. Nesse momento a agricultura latino-americana, como um todo, funcionou a serviço da indústria e na conformação dos complexos agroindustriais. Caracterizou-se, ainda, pelo desenvolvimento nacional e industrial, baseado na política de substituição de importações.

Na sequência, predominou uma fase de liberalização e abertura econômica (19801990), marcada por atividades agrícolas de exportação e políticas de apoio aos empreendimentos agrícolas de grande porte. Posteriormente, instalou-se um período mais recente (que se desdobra desde os anos 1990), caracterizado por programas de compensação de falhas de mercado (SABOURIN et al., 2014, p. 21-22).

Ademais, tais periodizações não são estanques. Ao contrário, décadas como a faixa dos anos 1980 a 2000 demonstram diversas variantes da agricultura entre países latinoamericanos. Mesmo com graus de diferenciação, a região passou por um contexto

\footnotetext{
${ }^{3}$ Conforme estudos de Barril e Almada (2007), Schjetman (2008), Márques e Ramos (2012), Piadal (2013) e outros autores da bibliografia especializada.
} 
relativamente comum de impactos da globalização, abertura de mercados, privatizações e ajustes estruturais ou financeiros, estes marcadamente entre 1994 e 2001. A "Revolução Verde" encontrou seu ápice no campo, desdobrando-se na "intensificación selectiva del apoyo a la agricultura empresarial y comercial, lo que Silva (1982) llamó la modernización dolorosa y conservadora". Como resultado, a marginalização e pauperização da agricultura familiar tornou evidente "un proceso de polarización de la agricultura latinoamericana entre formas de producción campesinas y patronales" (SABOURIN et al., 2014, p. 21-22). Apesar dessa polarização, durante os anos 1980 e 1990, a agricultura familiar, ainda comumente chamada de camponesa, passou quase que desapercebida pela maioria dos países da América Latina. O conceito mais utilizado e desenvolvido foi o de campesinato, que desde as décadas de 1970 e 1980, foi revisitado por estudos baseados nas teorias de Chayanov (1974), disseminados na região (BARRIL; ALMADA, 2007, p. 03-05).

Assim, grosso modo, embora as organizações não-governamentais (ONG's), universidades e organismos de cooperação adotassem o termo "agricultura familiar", somente a partir dos anos 2000, o conceito e seu uso foram popularizados nos meios políticos, acadêmicos e movimentos sociais da América Latina (DE LA O; GARNER, 2012).

Nessa trajetória, o termo e as discussões sobre agricultura familiar na América Latina permaneceram como herdeiras das "reflexões sobre o campesinato, durante a década de 1970 e sobre a produção de pequena escala durante os anos 1990". Porém, aspectos novos foram agregados ao debate. Por exemplo, a discussão sobre a agricultura familiar "não retoma com tanta força os aspectos políticos e ideológicos que marcaram fortemente as discussões sobre o camponês e seu potencial revolucionário, nas décadas de 1960 e 1970" em toda a América Latina. Por outro lado, caminharam mais além da discussão "sobre eficiência e/ou sobre a eficiência da produção de pequena escala, que tiveram tanto impacto nas décadas de 1980 e 1990" (SCHNEIDER, 2014, p. 07-08).

Além disso, a difusão e reconhecimento do termo agricultura familiar ocorreu em meio ao ímpeto de modernização do meio rural. Esse ímpeto que alavancou a 
produtividade econômica, também aprofundou as desigualdades de acesso à terra, crédito e informações, resultando em aumentos da migração rural-urbana e em disputas por terra e água, além do agravamento da concentração de terras (SCHEJTMAN, 2008). Assim, as diferenças socioeconômicas entre a agricultura empresarial (ou agronegócio) e agricultura familiar evidenciaram a definição de sujeitos políticos com visões de mundo distintas, tornando cada vez mais aguda e violenta a luta por terra, território, direitos e identidades sociais (CASTRO, 2015). Esse reconhecimento foi além de uma mera difusão de termos técnicos. Significou um movimento ou esforço cognitivo de reexame e renomeação das formas com que os camponeses e os pequenos produtores foram definidos e tratados nas décadas anteriores (SCHNEIDER , 2014, p. 08).

Assim, desde o início do século XXI, um relativo consenso foi se formando entre estudiosos e formuladores de políticas públicas na América Latina, através da percepção de que as unidades familiares "não são necessariamente nem pobres, nem pequenas, nem muito menos desconectadas dos mercados, das cidades e da dinâmica social mais geral". Denotariam também múltiplas conexões, inclusive com "o estado nacional (através de políticas públicas) e, de maneira mais geral, com o questionamento dos efeitos homogeneizantes da globalização sociocultural. Essas variações levaram a uma série de estudos e investigações para criar marcos referenciais, tais quais aqueles desenvolvidos no âmbito da CEPAL (1984), FAO (2007) e da "Red Especializada para la Agricultura Familiar" (REAF), do Mercosul. Ademais, somente em 2004, a expressão "agricultura familiar" foi pela primeira vez reconhecida oficialmente na América Latina, através da Reunião Especializada de Agricultura Familiar (REAF) do MERCOSUL. Apesar do processo de conhecimento e definição da agricultura familiar operar no plano da institucionalidade formal, esse esforço tem levado, na prática, a um melhor posicionamento e visibilidade do setor na sociedade e nas agendas governamentais (DE LA O; GARNER, 2012).

Por fim, a agricultura familiar vem se configurando, na América Latina como um todo, como categoria política emergente (SCHNEIDER, 2012), tanto pelo aumento da 
legitimidade social, quanto pela visibilidade de suas demandas por terra, direitos e políticas públicas.

\section{DEFINIÇÕES DE AGRICULTURA FAMILIAR NA AMÉRICA LATINA}

Uma das definições técnicas mais antigas sobre agricultura familiar latino-americana vem de meados do século XX. Trata-se do termo "unidad economica familiar" (unidade econômica familiar), cujo sentido normativo coincide, em grande parte, com o de "módulo fiscal"4, adotado pelo Instituto Nacional de Colonização e Reforma Agrária do Brasil (INCRA). Sua significação, dentre outras denominações, foi utilizada por quase todos os países latino americanos em projetos de reforma agrária, assumindo finalidades analíticas e políticas (MALETTA, 2011, p. 08; SCHNEIDER, 2012; CASTRO, 2013).

A unidade econômica familiar é uma gleba de tamanho suficiente para prover o sustento de uma família. Seu funcionamento requer a mão-de-obra estritamente familiar e não contratada. A partir desse conceito, a definição de agricultura familiar foi historicamente identificada com a ideia de "uma terra trabalhada pela família, associando a contratação de trabalhadores assalariados com a exploração capitalista" (MALETTA, 2011, p. 08).

En una mención a las raíces del concepto de agricultura familiar en aquellas concepciones utópicas y populistas se puede exponer que las raíces populistas del concepto originan algunas de sus características definitorias, como por ejemplo la idea de una finca familiar que no utiliza mano de obra asalariada. La contratación de trabajadores es (implícita o explícitamente) considerada como una degradación del ideal de la finca familiar, porque el uso de personal asalariado se asocia con la explotación capitalista. (MALETTA, 2011, p. 08, grifo nosso).

\footnotetext{
${ }^{4} \mathrm{O}$ módulo fiscal, no Brasil, corresponde à área mínima necessária a uma propriedade rural para que sua exploração seja economicamente viável. O tamanho do módulo fiscal para cada município brasileiro está fixado através de Instruções Especiais (IE) expedidas pelo INCRA, de acordo com a Lei no 8.629/93. O módulo fiscal também é parâmetro para a classificação fundiária do imóvel rural, sendo minifúndio o imóvel rural de área inferior a 1 (um) módulo fiscal; pequena propriedade o imóvel rural entre 1 (um) e 4 (quatro) módulos fiscais; média propriedade aquele de área entre 4 (quatro) e 15 (quinze) módulos fiscais e grande propriedade aquela superior a 15 (quinze) módulos fiscais.
} 
Decorrendo de tal lógica, mas sem adotá-la com radicalidade, a agricultura familiar vem sendo entendida como o exercício de uma atividade econômica por parte de um grupo social unido por laços de parentesco e de consanguinidade. É, economicamente, um grupo social que trabalha e produz bens e serviços e, socialmente, adota uma forma de trabalho e de produção, em que a atividade (agricultura) se concretiza no núcleo doméstico e familiar (SCHNEIDER, 2009, p. 09).

Essa concepção, porém, desdobra-se em diferentes práticas na América Latina, assumindo denominações e regulamentações peculiares, como algumas exemplificadas no quadro seguinte ${ }^{5}$ :

Quadro 1 - Denominação e critérios para a agricultura familiar em alguns países latino-americanos

\begin{tabular}{|c|c|c|c|c|c|c|}
\hline PAÍSES & $\begin{array}{c}\text { DENOMINAÇÃ } \\
0\end{array}$ & $\begin{array}{l}\text { SUPERFÍCIE E } \\
\text { CAPITAL }\end{array}$ & TRABALHO & $\begin{array}{l}\text { GESTÃO OU } \\
\text { ATIVIDADE }\end{array}$ & RENDA & RESIDÊNCIA \\
\hline ARGENTINA & $\begin{array}{l}\text { Pequeño } \\
\text { produtor } \\
\text { agropecuario }\end{array}$ & $\begin{array}{l}\text { Limite por } \\
\text { região }\end{array}$ & $\begin{array}{l}\text { Sem assalariado } \\
\text { permanente }\end{array}$ & $\begin{array}{l}\text { Trabalho } \\
\text { direto sobre } \\
\text { a terra }\end{array}$ & Sem limite & Sem critério \\
\hline BRASIL & $\begin{array}{l}\text { Agricultor } \\
\text { Familiar }\end{array}$ & $\begin{array}{l}\text { Até } 4 \text { módulos } \\
\text { fiscais }\end{array}$ & $\begin{array}{l}\text { Até } 01 \text { ou } 02 \\
\text { assalariados } \\
\text { permanentes }\end{array}$ & $\begin{array}{l}\text { Gestão } \\
\text { familiar }\end{array}$ & $\begin{array}{l}70 \% \text { de renda } \\
\text { familiar da } \\
\text { terra }\end{array}$ & $\begin{array}{l}\text { Residir na } \\
\text { terra }\end{array}$ \\
\hline CHILE & $\begin{array}{l}\text { Agricultor } \\
\text { familiar } \\
\text { campesino }\end{array}$ & $\begin{array}{l}\text { Até } 12 \\
\text { hectares de } \\
\text { irrigação } \\
\text { básica e ativos } \\
\text { menores que } \\
96 \text { mil USD } \\
\end{array}$ & $\begin{array}{l}\text { Trabalho de } \\
\text { familiares } \\
\text { diretamente } \\
\text { sobre a terra }\end{array}$ & $\begin{array}{l}\text { Trabalho } \\
\text { direto sobre } \\
\text { a terra }\end{array}$ & $\begin{array}{l}\text { Renda } \\
\text { principal ser } \\
\text { familiar na } \\
\text { unidade }\end{array}$ & Sem critério \\
\hline COLÔMBIA & $\begin{array}{l}\text { Unidad } \\
\text { Agricola } \\
\text { Familiar (UAF) }\end{array}$ & $\begin{array}{l}\text { UAF com } \\
\text { patrimônio } \\
\text { familiar }\end{array}$ & $\begin{array}{l}\text { Trabalho de } \\
\text { familiares } \\
\text { diretamente } \\
\text { sobre a terra, } \\
\text { mas com } \\
\text { possibilidade de } \\
\text { assalariados }\end{array}$ & $\begin{array}{l}\text { Trabalho } \\
\text { baseado na } \\
\text { atividade } \\
\text { agropecuári } \\
\text { a, aquícola e } \\
\text { florestal }\end{array}$ & Sem limite & Sem critério \\
\hline PARAGUAI & $\begin{array}{l}\text { Agricultura } \\
\text { Familiar } \\
\text { Camponesa }\end{array}$ & $\begin{array}{l}\text { Sem nenhum } \\
\text { limite }\end{array}$ & $\begin{array}{l}\text { Trabalho de } \\
\text { familiares } \\
\text { diretamente } \\
\text { sobre a terra, }\end{array}$ & $\begin{array}{l}\text { Gestão pela } \\
\text { família }\end{array}$ & Sem limite & $\begin{array}{l}\text { Residir na } \\
\text { unidade } \\
\text { familiar ou } \\
\text { em suas }\end{array}$ \\
\hline
\end{tabular}

\footnotetext{
${ }^{5}$ Dados extraídos de FAO, 2012b, CEPAL et al, 2013; SALCEDO Y GUZMAN, 2014 e de Argentina SAGPyA 1998 e Proinder 2004; Brasil: Lei 11.326, 2006; Chile: Instituto de Desarrollo Agropecuario-INDAP; Colombia: Lei 160/1994; Paraguai: Lei no 2419, Instituto Nacional de Desarrollo Rural y Tierra, 2004; Uruguay: Ministerio Ganadería Agrícola y Pesca - MGAP, 2008, Registro de Productor Familiar, 2009.
} 


\begin{tabular}{|l|l|l|l|l|l|l|}
\hline & & & $\begin{array}{l}\text { podendo ser } \\
\text { contratados até } \\
\text { 20 assalariados }\end{array}$ & & cercanias \\
\hline URUGUAI & $\begin{array}{l}\text { Productor } \\
\text { Familiar }\end{array}$ & $\begin{array}{l}\text { Até } 500 \\
\text { hectares } \\
\text { (índice } 100 \\
\text { Coneat } \\
\text { urugruaio) }\end{array}$ & $\begin{array}{l}\text { Trabalho de } \\
\text { familiares } \\
\text { diretamente } \\
\text { sobre a terra, } \\
\text { podendo haver } \\
\text { até 02 salários } \\
\text { permanentes ou } \\
500 \text { jornadas } \\
\text { por ano }\end{array}$ & $\begin{array}{l}\text { Gestão } \\
\text { Familiar “o } \\
\text { jefe de } \\
\text { família" }\end{array}$ & $\begin{array}{l}\text { Renda e } \\
\text { trabalho } \\
\text { familiares } \\
\text { sobre a terra }\end{array}$ & $\begin{array}{l}\text { Até } 50 \\
\text { quilômetros } \\
\text { da unidade } \\
\text { familiar }\end{array}$ \\
& & & & \\
\hline
\end{tabular}

Fonte: SABOURIN; SAMPER; SOTOMAYOR (2014, p. 28)

Pelo quadro acima, fica evidente a diversidade de termos e limites de definição técnica que permeiam a categoria social. Ao analisar tais nuances, a agricultura familiar latino-americana é, com todas as suas diferenças internas, um espaço social que "não significa uma ruptura total e definitiva com as formas anteriores, devendo o agricultor familiar adaptar-se as novas exigências da sociedade, sem desvincular-se das tradições camponesas" (WANDERLEY, 2009, p. 41-43).

Assim, a conceituação e a prática da agricultura familiar designa conceitos "como o tradicional camponês, o agricultor de subsistência e o pequeno produtor rural, e incorpora, conceitualmente, os desafios da modernidade". Ela se reproduz nas sociedades contemporâneas e "deve adaptar-se a um contexto socioeconômico próprio dessas sociedades, as quais levam a modificações importantes nas formas de vida social tradicionais" (WANDERLEY, 1999, p. 02). Nesse contexto, o termo agricultura familiar se desdobra em diversas outras denominações, a exemplo da Argentina (Pequeño Productor Agropecuario), Brasil (Agricultor Familiar), Chile (Agricultor familiar campesino), Colômbia (Unidad Agrícola Familiar-UAF), Paraguai (Agricultura Familiar Campesina), Uruguai (Productor Familiar), bem como Agricultura Familiar Agroecológica Campesina (AFAC), na Comunidade Andina. 
Com todas as diferenças terminológicas, a noção de agricultura familiar converge como "conceitos-síntese", isto é, "mais que simples categorias empíricas, à medida que teriam uma construção, apropriação e uso voltados para a expressão de identidades sociais" (SAUER, 2008, p. 67). Assim, no âmago da diversidade, há, em comum, "uma racionalidade intrínseca ao agricultor familiar, que consiste em ultrapassar o pacto capitalterra, criando novas visões sobre o que seja desenvolvimento econômico, social e político" (CASTRO, 2013, p. 76).

Exemplo disso é a percepção das vantagens ou desvantagens do ambiente institucional, que se submete a um "arranjo de cosmovisões", isto é, se insere em "uma unidade que, do ponto de vista operacional e cultural é, ao mesmo tempo, estrutura de produção, de consumo e de reprodução sociocultural". Ideias como "progresso, desenvolvimento e modernização estão vinculadas à produção combinada de valores de uso e de mercadorias, objetivando, para além da renda, do lucro ou da comercialização, a reprodução social" (CASTRO, 2015, p. 99). Diante disso, argumentos puramente econômicos (renda ou produtividade) ou argumentos somente jurídicos (segurança ou insegurança do direito de propriedade) não são suficientes para compreender a lógica da agricultura familiar, especialmente no que tange ao acesso à terra, valorada reflexamente como lugar de vida, de cidadania e de direitos fundamentais (SAUER; CASTRO, 2012; CASTRO, 2015, p. 102).

Nessa linha, a agricultura familiar representa, não somente uma categoria social, mas também uma categoria de sujeitos políticos que constrói visões de mundo próprias, acerca da terra e das formas de produzir bens e serviços. Por conseguinte, é diversa, ampla e extensa. Existe na América Latina, de um país para outro e dentro dos próprios países, sob uma diversidade de situações históricas, sociais e técnico-produtivas de múltiplos segmentos de produtores agropecuários, transmudando-se ora em "agricultura campesina", "pequeña agricultura" ou "producción a pequeña escala" (MARQUES; RAMOS, 2012; PIADAL, 2013). 
Não obstante, sua amplitude, há um sentido analítico e político. A agricultura familiar sob a perspectiva de uma "categoría social diversa y heterogénea" se consolidou pelo "papel estratégico en el proceso de desarrollo social y económico de los países de la región". Portanto, adquiriu "una centralidad política tanto para las organizaciones internacionales como para los movimientos sociales, los sindicatos y las cooperativas, al igual que para los partidos políticos y para los programas y las políticas públicos" (SCHNEIDER, 2014, p. 08).

Assim, como um "guarda-chuva conceitual", o termo agricultura familiar na América Latina abriga "grande número de situações, em contraposição à agricultura patronal, tendo como ponto focal da polarização os tipos de mão-de-obra e de gestão", os quais são essencialmente familiares. As unidades de produção familiar seriam "formas de conexão, de disjunção e de conjunção", sistemas de "procedimentos e de estratégias e não uma estrutura dada, a qual aos indivíduos só cabe a própria modelação (NEVES, 1995, p. 34).

\section{AGRICULTURA FAMILIAR E AMÉRICA LATINA: POTENCIALIDADES, RUPTURAS E PERSPECTIVAS}

O meio rural é, a despeito de toda diversidade entre países latino-americanos, de forma geral, um espaço excludente e concentrador, cujas raízes remontam a práticas coloniais. Essas práticas dizem respeito a "uma estrutura complexa de níveis entrelaçados" (MIGNOLO, 2010, p.12), baseada em um amplo sistema de controle da economia, da autoridade, da natureza e dos recursos naturais, do gênero e da sexualidade, da subjetividade e do conhecimento (BALLESTRIN, 2013, p. 99-100).

Nesse contexto, a agricultura familiar na América Latina se insere, historicamente, no campo das lutas e demandas por parte "daqueles segmentos que, mesmo centrando no meio rural suas expectativas de vida, produção, consumo e conquista da cidadania, sempre estiveram excluídos" do acesso à terra, direitos e cidadania (SAUER; LEITE, 2012, p. 506). 
Essa exclusão pode ser interpretada a partir das relações de colonialidade. Isto é, como relações que, em especial nas esferas econômica e política sobre a terra, não findaram com a destruição do colonialismo. Há, sobremaneira, "uma continuidade das formas coloniais de dominação após o fim das administrações coloniais, produzidas pelas culturas coloniais e pelas estruturas do sistema-mundo capitalista moderno/colonial" (GROSFOGUEL, 2008, p.126).

Assim, o processo colonial inicia o ciclo de aproveitamento econômico das terras e recursos latino-americanos, que ao longo de séculos, mantém-se dentro de pactos de poder político e social, nos quais "a grande propriedade, dominante em toda a sua História, se impôs como modelo socialmente reconhecido" (WANDERLEY, 1999).

Nessa lógica, a formação interna de elites agrárias, projetos como a Revolução Verde e alianças nacionais e internacionais sobre a terra e seus recursos são formas que, em momentos posteriores à realidade colonial, atualizam e contemporizam processos que supostamente teriam sido apagados, assimilados ou superados pela modernidade (BALLESTRIN, 2013, p. 99-100). Nesse vasto e intrincado cenário:

[...] aparecem semelhanças, convergências e contemporaneidades. Multiplicamse e repetem-se formas de sociabilidade e jogos de forças sociais, estruturas de dominação e apropriação, compreendendo patrimonialismos, tais como caciquismo, gamonalismo e coronelismo; oligarquias locais, regionais e nacionais; de par-em-par com tradicionalismos e modernismos, reivindicações e rebeldias de setores sociais subalternos, revoltas e revoluções (IANNI, 2000, p. 05).

Assim, as raízes coloniais aludem não somente à estruturação de acessos sob a lógica do mercantilismo bulionista ou da implantação de plantations, haciendas $e$ sesmarias. Refere-se também a "situações de opressão diversas, definidas a partir de fronteiras de gênero, étnicas e raciais" (BALLESTRIN, 2013, p. 90) que recaem sobre a propriedade da terra e seus recursos, sistematicamente capturados por grupos de poder. As consequências do colonialismo reforçam e reproduzem indiretamente as formas de dominação e exclusão sobre a terra, pois, ainda que não haja colonialismo sem exploração 
ou opressão, a exploração e a opressão "do passado" podem ser reatualizadas sem o colonialismo (BALLESTRIN, 2013), mas por outras dinâmicas de poder que reafirmam a concentração de terras, capital e informação.

Nesse contexto, a construção das identidades "vale-se de matéria-prima fornecida pela história, geografia, biologia, instituições produtivas e reprodutivas, pela memória coletiva e por fantasias pessoais, pelos aparatos de poder e revelações de cunho religioso" (CASTELLS, 1996, p.23). Esse processo é, em grande medida, determinado pelo seu conteúdo simbólico, isto é, a construção das identidades dos agricultores familiares ocorre sempre em um contexto marcado por relações de poder.

Exemplo dessas rupturas e continuidades são as políticas agrícolas. Piadal (2013), através de estudos de caso, aponta um conjunto fragmentado de acordos parciais que são o resultado de negociações privadas, entre grupos de interesse e coalizões de setores empoderados. Normalmente, esses acordos não são orientados por uma estratégia global ou abrangente de desenvolvimento da agricultura familiar. Ao contrário disso, os anseios de "modernização da agricultura" permanecem profundamente vinculados à ideia de progresso. Mas, qual progresso? Nesse sentido, a implantação da Revolução Verde, através de um amplo programa de crédito e outros incentivos governamentais, consolidou a concepção de progresso no campo como produção baseada na combinação intensiva de tecnologia, capitais e informações - elementos que os agricultores familiares são, historicamente, privados de acesso por inúmeros fatores (FAO/BID, 2007; SAUER, 2010; CASTRO, 2015).

Sob a égide da Revolução Verde (implantada a partir de meados do século XX), a agricultura ficou relegada a funções técnicas (tais como liberar mão-de-obra, fornecer matérias-primas, transferir capital e gerar divisas) e a terra enquadrada em "uma lógica territorial que tem concebido grandes áreas do espaço geográfico latino-americano como "vazios demográficos" ou "terras disponíveis". Essa forma de conceber o espaço geográfico 
latino-americano remonta ao legado colonial que atravessa a formação sócio espacial da região" (PORTO-GONÇALVES; QUENTAL, 2012).

Em meio a semelhanças e convergências, a identidade social da agricultura familiar também se mostra como uma diversidade que admite diferenciações internas, traduzindo as disparidades que permeiam a realidade latino-americana. Por isso, em países como Brasil, Chile, Colômbia, Equador, México e Nicarágua é possível identificar categorias de agricultura familiar.

Nesse sentido, há a agricultura familiar de subsistência (AFS), caracterizada por estar em condição de insegurança alimentar, escassez de terra, privação de crédito e ingressos insuficientes. Geralmente estão inseridos em ecossistemas frágeis de áreas tropicais ou de montanha, configurando a extrema pobreza rural. Há, ainda, a agricultura familiar de transição (AFT), que emprega técnicas para conservar recursos naturais e conta com maiores recursos agropecuários. Tem maior potencial produtivo e para vendas. Possui recursos para reprodução social da unidade familiar, mas está privada de gerar excedentes suficientes para desenvolver sua unidade produtiva, por contar com limitações significativas de crédito e acesso aos mercados. Por fim, há a agricultura familiar consolidada ( $\mathrm{AFC})$, que dispõe de um maior potencial de recursos agropecuários, capazes de gerar excedentes para a capitalização de sua vida produtiva. Está mais integrada ao setor comercial, às cadeias produtivas, insumos e recursos naturais, podendo superar a pobreza rural (FAO/BID, 2007). A título de exemplificação, vejamos a seguinte distribuição:

Quadro 2 - Diferenciações internas da agricultura familiar em alguns países latino-americanos

\begin{tabular}{|l|l|l|l|}
\hline \multicolumn{1}{|c|}{ PAÍS } & $\begin{array}{c}\text { PERCENTUAL DE } \\
\text { AGRICULTURA FAMILIAR DE } \\
\text { SUBSISTÊNCIA (AFS) }\end{array}$ & $\begin{array}{c}\text { PERCENTUAL DE } \\
\text { AGRICULTURA FAMILIAR DE } \\
\text { TRANSIÇÃO (AFT) }\end{array}$ & $\begin{array}{c}\text { PERCENTUAL DE } \\
\text { AGRICULTURA FAMILIAR } \\
\text { CONSOLIDADA (AFC) }\end{array}$ \\
\hline BOLÍVIA & 67,2 & 22,8 & 10 \\
\hline COLÔMBIA & 79,4 & 12,9 & 7,7 \\
\hline EQUADOR & 61,6 & 37 & 1,4 \\
\hline PERU & 45,5 & 35,4 & 19,1 \\
\hline
\end{tabular}

Fonte: CAN (2011); FAO/BID (2007). 
Esses extratos se formam a partir dos contextos mais diversos de dificuldades de acesso à terra, capital e informação que permeiam distintos países latino-americanos (FAO/BID, 2007). De forma, geral, forma-se uma hegemonia a partir do topo, [que envolve] grandes propriedades, cadeias agroindustriais estreitamente ligadas ao setor externo e as burocracias do Estado", permitindo a acumulação de capital garantida por recursos e incentivos públicos (DELGADO, 2013, p. 62).

Entre outras consequências, há uma exacerbação das disputas territoriais ou "conflitos em relação aos modelos concorrentes de desenvolvimento e territórios" (FERNANDES et al., 2012, p. 37).

Essas disputas pressupõem a negação de direitos, tais como os direitos territoriais dos povos indígenas e outras comunidades tradicionais, aumentando lutas por terra e território (SAUER, 2012). Contudo, essas disparidades vêm sendo questionadas e combatidas também pelos agricultores familiares. Nessa perspectiva, o meio rural latino americano é um "espaço institucional mais amplo de lutas" (CASTRO, 2013, p.11), em que diversas categorias sociais convergem suas demandas por "libertação e emancipação, na qual a busca por sobrevivência e reprodução social inclui reivindicações por saúde, educação, justiça e paz" (SAUER, 2003, p. 15).

Assim, os agricultores familiares constroem narrativas, discursos e atuam através de movimentos sociais, ocupações, invasões, formação de assentamentos e organizações, bem como nas lutas por reforma agrária e outras formas de resistência e reivindicação.

No Brasil, historicamente, os movimentos sociais agrários e entidades do campo intensificaram as mobilizações e lutas, especialmente a partir dos anos 1980. Lideradas pelo Movimento dos Trabalhadores Sem-Terra (MST), as ocupações de terra se espalharam por todo o país (MARTINS, 1994), resultando em uma série de políticas governamentais, especificamente a de assentamentos agrários e de fortalecimento da agricultura familiar (SAUER, 2016). 
No âmbito da formação de redes, organizações e movimentos, existe, desde os anos 1990, a "Associação de Organizações de Produtores Ecológicos da Bolívia" (AOPEB), que reúne cerca de 76 entidades e promove a produção da agricultura familiar com base no resgate e na revalorização dos sistemas tradicionais e sustentáveis. Os protagonistas são pequenos produtores, camponeses e indígenas que, através de suas comunidades, associações e cooperativas mobilizam mais de 60 mil agricultores nas culturas de cereais, frutas, tubérculos, hortaliças, soja, algodão e sorgo (CAN, 2011).

$\mathrm{Na}$ Colômbia, a "Red de Mercados Agroecológicos del Valle del Cauca" é um exemplo de como os agricultores familiares engendram estratégias peculiares de agir e viver. Uma delas são as feiras locais e tendas especializadas que dispensam o uso de certificações formais, pois se prioriza a proximidade entre produtores e consumidores de forma que as trocas se baseiem na confiança mútua. Os primeiros passos foram dados em 2006, através do Primeiro Encontro Nacional sobre "sistemas de certificação de confiança". Atualmente, mais de 60 organizações de base e de redes vinculam-se à certificação participativa, consolidando 15 espaços de comercialização em feiras e pontos permanentes em departamentos como Cauca, Valle,Quindío, Antioquia, Córdoba, Sucre y Nariño (CAN, 2011).

No Peru, os agricultores familiares se organizaram a "Red de Agricultura Ecológica" e a "Red de Alternativas al Uso de Agroquímicos", chegando à "Asociación Nacional de Productores Ecológicos" e à formação do "Consorcio Agroecológico del Perú" (CAEP). Aos poucos foram constituindo a certificação de produção, transformação e comercialização de produtos, como a Biolatina (CAN, 2011).

As mobilizações alcançam também avanços no plano institucional, com viés mais político. No Equador, agricultores familiares obtiveram importantes conquistas, como as Escuelas de la Revolución Agraria, a Mesa Nacional de Mercados, "un Plan de Tierras con carácter redistributivo, un Instituto de Economía Popular y Solidaria, además del impulso 
que viene dando el Ministerio de Agricultura y Ganadería a las ferias agropecuariasciudadanas, entre otras" (CAN, 2011, p. 40).

Essas, e outras dinâmicas, demonstram que a agricultura familiar latino-americana representa não somente uma categoria social, mas também um conjunto heterogêneo de sujeitos políticos, que constroem visões de mundo próprias, acerca da terra e das formas de produzir bens e serviços. Embora não se possa falar em um projeto de desenvolvimento "exclusivo" da "Agricultura Familiar", é possível identificar nas peculiaridades culturais da categoria, elementos implícitos à forma de agir e de viver, que apontam para formas sustentáveis de desenvolvimento social e econômico, tanto no rural, quanto no nacional (CASTRO, 2015, p. 96).

\section{CONCLUSÃO}

A abordagem sobre a agricultura familiar latino-americana, como atividade econômica produtiva dotada de tipificações jurídicas, é possível, mas é insuficiente para abarcar suas múltiplas facetas.

A diversidade de segmentos da categoria social manifesta modos e meios de vida, que traduzem parte dos contextos políticos, econômicos, sociais e culturais mais gerais da realidade latino-americana, em especial a concentração, a pobreza e exclusão fundiárias.

Diante dessa lógica, como estratégia de resistência e capacidade adaptativa, a agricultura familiar combina um conjunto de atividades econômicas, cooperação comunitária, processos culturais e identitários (certificações por confiança, feiras, pontos permanentes, escolas, etc.), que resultam diferentes alternativas de produção em redes, organizações e mobilizações.

Nesse sentido, há relações de proximidade, localização e aglutinação, como também relações sociais de diversas índoles (tais como de reciprocidade e colaboração, de parentesco, de vizinhança, de tradição, etc). Por tais especificidades, a natureza social e 
territorial da agricultura familiar latino-americana apresenta potencial "para favorecer su desarrollo integral" (SABOURIN et al, 2014, p. 39).

Como um "guarda-chuva conceitual", o termo abriga "grande número de situações, em contraposição à agricultura patronal, tendo como ponto focal da polarização os tipos de mão-de-obra e de gestão", os quais são essencialmente familiares. As unidades de produção familiar seriam "formas de conexão, de disjunção e de conjunção", sistemas de “procedimentos e de estratégias e não uma estrutura dada, a qual aos indivíduos só cabe a própria modelação (NEVES, 1995, p. 34).

Assim, a diversidade (presente nas definições e nas práticas de organização e produção) da agricultura familiar na América Latina coloca a categoria dentro, mas, para além da questão agropecuária. Isto é, manifesta-se como categoria social e sujeitos políticos, que se posicionam transversalmente a temas de envergadura regional e global, tais como a preservação do meio ambiente, luta contra a pobreza e desigualdade, segurança e soberania alimentar, educação, saúde e desenvolvimento territorial.

\section{REFERÊNCIAS}

BARRIL, G., A. e ALMADA, F. La agricultura familiar en los países del cono sur. Asunción: IICA, 2007.

CAN, Comunidad Andina de Naciones. Agricultura familiar agroecológica campesina en la comunidad andina. Una opción para mejorar la seguridad alimentaria y conservar la biodiversidad, Secretaría General de la Comunidad Andina(Perú): AECID, 2011.

CASTELLS, M. O poder da identidade, v. II. São Paulo: Paz e Terra, 1996.

CASTRO-GOMEZ, S. Ciências sociais, violência epistêmica e o problema da 'invencao do outro. In LANDER, Edgardo (org.). A colonialidade do saber: eurocentrismo e ciências sociais, perspectivas latino-americanas. Buenos Aires: Clacso, 2005. 
CASTRO, L. F. P. Agricultura familiar, habitus e acesso à terra. Revista Brasileira de Sociologia do Direito, ABraSD, v. 2, n. 2, p. 91-105, jul./dez., 2015. DOI: DOI: http://dx.doi.org/10.21910/rbsd.v2n2.2015.17. Acesso em: 01 jul. 2016.

CASTRO, L. F. P.; SAUER, S. A problemática e as condicionantes dos arrendamentos rurais na agricultura familiar. Anais do 50 Congresso da SOBER, Espírito Santo, Vitória, 2012. Disponível em: http://icongresso.itarget.com.br/useradm/anais/?clt=ser.2. Acesso em: 01 jul. 2016.

CASTRO, L.F.P. Dimensões e lógicas do arrendamento rural na agricultura familiar. Dissertação (mestrado em Agronegócios). Brasília: Universidade de Brasília, 2013.

CHAYANOV, V. A. La organización de la unidad económica campesina. Argentina: Nueva Visión, 1974.

. The socioeconomic natura of the peasant farm economy. En a systematic source book in rural sociology. Minneapolis: University of Minnesota Press, 1974.

COSTA, S. Dois Atlânticos: teoria social, anti-racismo e cosmopolitismo. Belo Horizonte: EdUFMG, 2006.

DE LA O, A.P; GARNER, E. Defining the "Family Farm". Working paper, FAO. 2012. Disponível em: http://www.fao.org/3/a-i4306e.pdf. Acesso em: 01 jul. 2016.

DELGADO, G. Economia do agronegócio (anos 2000) como pacto do poder com os donos da terra. Revista Reforma Agrária, Brasília, ABRA, edição especial, 2013. Disponível em: http://www.agroecologia.org.br/files/importedmedia/revista-abra-agronegocio-erealidade-agraria-no-brasil.pdf. Acesso em: 01 jul. 2016.

FAO (Organización de las Naciones Unidas para la Alimentación y la Agricultura); BID (Banco Interamericano de Desarrollo). Políticas para la agricultura familiar en América Latina y el Caribe. F. Soto Baquero; M.R. Fazzone; C. Falconi (eds.). Santiago do Chile: Oficina Regional de la FAO para América Latina y el Caribe, 2007.

. Marco estratégico de mediano plazo de cooperación de la FAO en Agricultura Familiar en América Latina y el Caribe 2012 - 2015. Disponível em: http://www.rlc.fao.org/es/publicaciones/marco-estrategico-cooperacion-faoagriculturafamiliar-alc/. Acesso em: 01 jul. 2016.

FARRET, R.; PINTO, S. R. América Latina: da construção do nome à consolidação da ideia. Topoi (Rio J.), Rio de Janeiro, v. 12, n. 23, p. 30-42, dec., 2011. Disponível em: <http://www.scielo.br/scielo.php?script=sci_arttext\&pid=S2237-

101X2011000200030\&lng=en\&nrm=iso>. Acesso em: 04 jul. 2016.

FERNANDES, B.M.; WELCH, C.A.; GONÇALVES, E.C. Land governance in Brazil. Framing the Debate Series, v. II. Rome: ILC, 2012. 
GROSFOGUEL, R. Para descolonizar os estudos de economia politica e os estudos poscoloniais: transmodernidade, pensamento de fronteira e colonialidade global. Revista Crítica de Ciências Sociais, n. 80, 2008. Disponível em: http://rccs.revues.org/697. Acesso em: 04 jul. 2016.

IANNI, O. Enigmas do pensamento latino-americano. São Paulo: Instituto de Estudos Avançados da Universidade de São Paulo, 2000.

INSTITUTO BRASILEIRO DE GEOGRAFIA E ESTATÍSTICA. Séries Estatísticas \& Séries Históricas. Censos Agropecuários (1920 a 1995/96). Rio de Janeiro, RJ: IBGE. 2013. Disponível em :http:www.ibge.gov.br/series_estatisticas/subtema.php?idsubtema=100. Acesso em: 15 set. 2015.

Censo Agropecuário 2006: Brasil, Grandes Regiões e Unidades da Federação. Rio

de Janeiro, RJ: IBGE. 2007.2 Disponível em:

http://ibge.gov.br/home/estatistica/economia/agropecuaria/censoagro/2006_segunda_a puracao/default.shtm. Acesso em: 15 set. 2015.

MALETTA, $\mathrm{H}$. Tendencias y perspectivas de la agricultura familiar en América Latina. Documento de Trabajo $\mathrm{N}^{\circ}$ 1. Proyecto Conocimiento y Cambio en Pobreza Rural $\mathrm{y}$ Desarrollo. Santiago do Chile: Rimisp, 2011.

MARQUES, S.; RAMOS, A. Las políticas diferenciadas para la agricultura familiar en el MERCOSUR. Contribución del diálogo político al diseño de las políticas públicas y la institucionalización. S.I.: FIDA, 2012.

MARTINS, J.S. O poder do atraso: ensaios de sociologia da história lenta. São Paulo: Hucitec, 1994.

MIGNOLO, W. Desobediencia epistémica: retórica de la modernidad, lógica de la colonialidad y gramática de la descolonialidad. Argentina: Ediciones del signo, 2010.

NEVES, D. P. Agricultura familiar: questões metodológicas. Revista Reforma Agrária, Campinas, v. 25, no. 02, p. 21-37, jan./abr., 1995.

PIADAL (Panel Independiente de Agricultura para el Desarrollo en América). Agricultura y desarrollo en América Latina: gobernanza y políticas públicas. Barrantes, R.; Berdegué, J; Janvry, A. de et al. Buenos Aires, Argentina, Teseo, 2013.

PORTO-GONÇALVES, C.W.; QUENTAL, P.A. Colonialidade do poder e os desafios da integração regional na América Latina, Polis. Revista Latino Americana, n. 31, dez., p. 1-28, 2012. Disponível em: https://polis.revues.org/3749. Acesso em: 04 jul. 2016.

ROJAS MIX, M. Los cien nombres de América. Barcelona: Lumen, 1991.

SALCEDO, S., e GUZMAN, L. Agricultura familiar en América Latina y el Caribe: recomendaciones de política. Santiago: FAO, 2014. 
SCHNEIDER, S. La agricultura familiar en América Latina. In: Abel Cassol. (Org.). La agricultura familiar en América Latina. Roma: FIDA, 2014. p. 73-102.

SABOURIN, E., SAMPER, M., e SOTOMAYOR ECHENIQUE. Políticas públicas y agriculturas familiares en América Latina y el Caribe: balance, desafíos y perspectivas. Comisión Económica para América Latina y el Caribe (CEPAL). Colección Documentos de Proyecto. 2014.

SAUER, S. A luta pela terra e a reinvenção do rural. Anais do XI Congresso de Sociologia, São Paulo: Campinas, $2003 . \quad$ Disponível em: file://C:/Users/neimfa/Downloads/sbs2003 gt11 sergio sauer.pdf. Acesso em: 04 jul. 2016.

Agricultura familiar versus agronegócio: a dinâmica sociopolítica do campo brasileiro. Brasília, DF: Embrapa Informação Tecnológica, 2008.

Popular, 2010.

Terra e modernidade: a reinvenção do campo brasileiro. São Paulo: Expressão

. O campo no Governo Lula: acordos com o agronegócio e embates nas políticas agrárias no Brasil. Latin American Perspectives. (forthcoming), 2016.

SAUER, S., LEITE, S.P. Agrarian structure, foreign investment in land, and land prices in Brazil. Journal of Peasants Studies. V. 39, n.34, p. 873-898, 2012.

SCHEJTMAN, A. Alcances sobre agricultura familiar en América Latina. Diálogo Rural Iberoamericano. Documento de trabajo no 21. Programa Dinámicas Territoriales Rurales. San Salvador, El Salvador: RIMISP, 2008.

SCHNEIDER, S. La agricultura familiar en América Latina. Fondo Nacional de Desarrollo Agrícola. S.I.: FIDA, 2014.

. La construcción del concepto de agricultura familiar en América Latina. II Taller de Expertos sobre Agricultura Familiar, 28 y 29 de agosto. San Salvador, El Salvador, 2012. Disponível em: http://www.rlc.fao.org/fileadmin/templates/ iniciativa/content/pdf/eventos/agric-fam-centroamerica-

2012/Construccion_del_concepto_de_Agricultura_Familiar_-_Sergio_Schneider.pdf. Acesso em: 01 jul. 2016.

SOUZA, A. América Latina, conceito e identidade: algumas reflexões da História. PRACS: Revista de Humanidades do Curso de Ciências Sociais da UNIFAP, Macapá, n. 4, p. 29-39, 2011.

TEDESCO, J. C. Agricultura familiar: realidades e perspectivas. Passo Fundo, RS: EdUPF, 2001. 
WANDERLEY, M. N. B. Raízes Históricas do Campesinato Brasileiro. In: João Carlos Tedesco. (Org.). Agricultura familiar: realidades e perspectivas. 1ed. Passo Fundo, RS: Universidade de Passo Fundo, 1999.

- Raízes históricas do campesinato brasileiro. In D. M. da Mota, E. D. Tavares e W. M. P. de M. Ivo (orgs.), Agricultura familiar em debate. Sergipe: Aracaju, EMBRAPA-CPATC, 1997.

- Reencontro com o Nordeste: Itinerários de pesquisa e construção do campo intelectual dos estudos rurais. Estudos de Sociologia, Recife, vol. S, n.1, p.1-132, 1999. Disponível em: <http://www.revista.ufpe.br/revsocio/index.php/revista/article/view/306>. Acesso em: 19 jul. 2016.

. O mundo rural brasileiro: acesso a bens e serviços e integração campo-cidade. Estudos Sociedade e Agricultura, Rio de Janeiro, UFRRJ, v. 17, n.1, 2009. Disponível em: http://r1.ufrri.br/esa/V2/ojs/index.php/esa/article/view/308/304.

Acesso em: 04 jul. 2016.

. Agricultura familiar e campesinato: rupturas e continuidades. In: WANDERLEY. M. N. B. O mundo rural como espaço de vida: reflexões sobre a propriedade da terra, agricultura familiar e ruralidade. Porto Alegre. EdUFRGS, p.185-200, 2009a.

. O agricultor familiar no Brasil: um ator social da construção do futuro. Revista Agriculturas: experiências em Agroecologia, Rio de Janeiro, AS-PTA, p. 33-45, $2009 \mathrm{~b}$. Disponível em: http://aspta.org.br/wp-content/uploads/2011/05/N\%C3\%BAmeroespecial.pdf. Acesso em: 04 jul. 2016. 